\title{
DNA methylation signature of chronic low-grade inflammation and its role in cardio-respiratory diseases
}

Matthias Wielscher ( $\square$ matthias.wielscher@meduniwien.ac.at)

Department of Dermatology, Medical University of Vienna,

\section{Pooja Mandaviya}

Erasmus University Medical Center

Brigitte Kuehnel

Helmholtz Zentrum Muenchen

Roby Joehanes

National Heart Lung \& Blood Institute

\section{Rima Mustafa}

Imperial College London https://orcid.org/0000-0003-2623-5337

\section{Oliver Robinson}

Imperial College London https://orcid.org/0000-0002-4735-0468

\section{Tao Zhang}

Shandong University

\section{Barbara Bodinier}

Imperial College London https://orcid.org/0000-0002-0781-3624

\section{Esther Walton}

University of Bath https://orcid.org/0000-0002-0935-2200

\section{Pashupati Mishra}

Tampere University

\section{Pascal Schlosser}

Faculty of Medicine and Medical Center - University of Freiburg https://orcid.org/0000-0002-8460-0462

\section{Rory Wilson}

Helmholtz Zentrum München https://orcid.org/0000-0001-6135-3764

\section{Pei-Chien Tsai}

Kings College London

\section{Saranya Palaniswamy}

Imperial College London https://orcid.org/0000-0003-4145-540X

\section{Riccardo Marioni}

University of Edinburgh

\section{Giovanni Fiorito}


University of Sassari

\section{Giovanni Cugliari}

Fondazione IRCCS Istituto Nazionale dei Tumori

\section{Ville Karhunen}

Imperial College London https://orcid.org/0000-0001-6064-1588

\section{Mohsen Ghanbari}

Erasmus University Medical Center https://orcid.org/0000-0002-9476-7143

\section{Bruce Psaty}

UW https://orcid.org/0000-0002-7278-2190

\section{Marie Loh}

https://orcid.org/0000-0003-3626-8466

\section{Joshua Bis}

University of Washington https://orcid.org/0000-0002-3409-1110

\section{Benjamin Lehne}

Imperial College London

\section{Nona Sotoodehnia}

Cardiovascular Health Research Unit, University of Washington Medical Center, Seattle

\section{lan Deary}

University of Edinburgh

\section{Marc Chadeau-Hyam}

Department of Epidemiology and Biostatistics, School of Public Health, Imperial College London, UK https://orcid.org/0000-0001-8341-5436

\section{Jennifer Brody}

University of Washington https://orcid.org/0000-0001-8509-148X

\section{Alexia Cardona}

University of Cambridge

\section{Elizabeth Selvin}

Johns Hopkins Bloomberg School of Public Health

\section{Alicia Smith}

Emory University https://orcid.org/0000-0002-8537-5156

\section{Andrew Miller}

Emory University School of Medicine https://orcid.org/0000-0001-8260-7997

\section{Mylin Torres}

Emory University School of Medicine, Winship Cancer Institute of Emory University, Atlanta

\section{Eirini Marouli}

William Harvey Research Institute, Barts and The London School of Medicine and Dentistry, Queen Mary University of London, London, UK https://orcid.org/0000-0001-6179-1609

\section{Xin Gào}

German Cancer Research Center https://orcid.org/0000-0003-0108-6961 


\section{Joyce van Meurs}

Erasmus University Medical Center

\section{Johanna Graf-Schindler}

Helmholtz Zentrum Muenchen

\section{Wolfgang Rathmann}

Leibniz Center for Diabetes Resesarch at Heinrich Heine University Duesseldorf

\section{Wolfgang Koenig}

Technical University Munich https://orcid.org/0000-0002-2064-9603

\section{Annette Peters}

Deutsches Forschungszentrum für Gesundheit und Umwelt (GmbH) https://orcid.org/0000-0001-66450985

\section{Wolfgang Weninger}

Medical University of Vienna

\section{Matthias Farlik}

Medical Universoty of Vienna https://orcid.org/0000-0003-0698-2992

\section{Yan Zhang}

German Cancer Research Center (DKFZ)

\section{Wei Chen}

Tulane University https://orcid.org/0000-0003-1566-7943

\section{Yujing Xia}

King's College London

\section{Alexander Teumer}

University Medicine Greifswald https://orcid.org/0000-0002-8309-094X

\section{Matthias Nauck}

University Medicine Greifswald https://orcid.org/0000-0002-6678-7964

\section{Hans Grabe}

University of Greifswald

\section{Marcus Dörr}

Ernst-Moritz-Arndt-University https://orcid.org/0000-0001-7471-475X

\section{Terho Lehtimäki}

Department of Clinical Chemistry, Fimlab Laboratories and Finnish Cardiovascular Research Center-

Tampere, Faculty of Medicine and Health Technology, Tampere University https://orcid.org/0000-00022555-4427

\section{Weihua Guan}

Division of Biostatistics, School of Public Health, University of Minnesota

\section{Lili Milani}

University of Tartu https://orcid.org/0000-0002-5323-3102

\section{Toshiko Tanaka}

National Institute on Aging 


\section{Krista Fischer}

University of Tartu

\section{Lindsay Waite}

Hudson Alpha Institute for Biotechnology

\section{Silva Kasela}

Estonian Genome Centre, Institute of Genomics, University of Tartu, Tartu, Estonia

\section{Paolo Vineis}

Imperial College London

\section{Niek Verweij}

University Medical Center Groningen

\section{Pim van der Harst}

University of Groningen https://orcid.org/0000-0002-2713-686X

\section{Licia lacoviello}

Research Center in Epidemiology and Preventive Medicine (EPIMED). Department of Medicine and

Surgery. University of Insubria, Varese

\section{Carlotta Sacerdote}

Italian Institute for Genomic Medicine (IIGM)

\section{Salvatore Panico}

Federico II University

\section{Vittorio Krogh}

Fondazione IRCCS Istituto Nazionale dei Tumori di Milano https://orcid.org/0000-0003-0122-8624

\section{Rosario Tumino}

Cancer Registry and Histopathology Department, "Civic - MPP Arezzo" Hospital

\section{Evangelia Tzala}

Imperial College London

\section{Giuseppe Matullo}

University of Turin

\section{Mikko Hurme}

University of Tampere

\section{Olli Raitakari}

University of Turku

\section{Elena Colicino}

Icahn School of Medicine at Mount Sinai, New York

\section{Andrea Baccarelli}

University Mailman School of Public Health

\section{Mika Kähönen}

Department of Clinical Physiology, Tampere University Hospital, and Finnish Cardiovascular Research Center - Tampere, Faculty of Medicine and Health Technology, Tampere University 
Oulu University https://orcid.org/0000-0003-4460-2604

Shengxu Li

Tulane University School of Public Health and Tropical Medicine https://orcid.org/0000-0001-92107283

\section{Bastiaan Heijmans}

Leiden University Medical Center https://orcid.org/0000-0001-5918-0534

\section{Karen Conneely}

Emory University School of Medicine

\section{Jaspal Kooner}

Imperial College London

\section{Anna Kottgen}

University Medical Center Freiburg https://orcid.org/0000-0002-4671-3714

\section{Panos Deloukas}

Queen Mary University of London https://orcid.org/0000-0001-9251-070X

\section{Caroline Relton}

University of Bristol

\section{Ken Ong}

University of Cambridge School of Clinical Medicine https://orcid.org/0000-0003-4689-7530

\section{Jordana Bell}

King's College London https://orcid.org/0000-0002-3858-5986

\section{Eric Boerwinkle}

The University of Texas Health Science Center at Houston

\section{Paul Elliott}

Imperial College London https://orcid.org/0000-0002-7511-5684

\section{Hermann Brenner}

German Cancer Research Center (DKFZ) https://orcid.org/0000-0002-6129-1572

\section{Marian Beekman}

Leiden University Medical Center https://orcid.org/0000-0003-0585-6206

\section{Daniel Levy}

National Heart Lung and Blood Institute

\section{Melanie Waldenberger}

Research Unit of Molecular Epidemiology, Helmholtz Zentrum München, German Research Center for Environmental Health, 85764 Neuherberg, Bavaria https://orcid.org/0000-0003-0583-5093

\section{John Chambers}

Nanyang Technological University

\section{Abbas Dehghan}

Department of Epidemiology and Biostatistics, Imperial College London, London

\section{Marjo-Riitta Jarvelin ( m.jarvelin@imperial.ac.uk)}

Imperial College London https://orcid.org/0000-0002-2149-0630 
Article

Keywords: DNA methylation, CRP, CpG

Posted Date: August 10th, 2021

DOl: https://doi.org/10.21203/rs.3.rs-688986/v1

License: (c) (1) This work is licensed under a Creative Commons Attribution 4.0 International License. Read Full License 


\section{Abstract}

We performed a trans-ethnic Epigenome Wide Association study on 22,774 individuals to describe the DNA methylation signature of chronic low-grade inflammation as measured by C-Reactive protein (CRP). We found 1,511 independent differentially methylated loci associated with CRP. These CpG sites showed correlation structures across chromosomes, and were primarily situated in euchromatin, depleted in CpG islands and enriched in transcription factor binding sites and genomic enhancer regions. Mendelian randomisation analysis suggests altered $\mathrm{CpG}$ methylation is a consequence of increased blood CRP levels. Mediation analysis revealed obesity and smoking as important underlying driving factors for changed $\mathrm{CpG}$ methylation. Finally, we found that a fully activated $\mathrm{CpG}$ signature, meaning that if all novel discovered $\mathrm{CpGs}$ would either be fully methylated or unmethylated depending on their CRP associated direction of effect, the risk of myocardial infarction would be increased by $20.3 \%$, risk of T2D by $11.3 \%$ and the risk of COPD by $5.6 \%$.

\section{Introduction}

In population-based studies, C-reactive protein (CRP)-an acute phase reactant-- is commonly used as a proxy for chronic low-grade inflammation ${ }^{1,2}$. Low-grade inflammation plays a key role in the development of a wide range of disease such as type 2 diabetes (T2D $)^{3,4}$, coronary heart and other cardiovascular diseases ${ }^{5}$, chronic obstructive pulmonary disease (COPD) ${ }^{6}$ as well as several psychological disorders such as post-traumatic stress syndrome, schizophrenia and depression ${ }^{7,8}$. Prior studies have strongly linked elevated serum CRP to genetics ${ }^{9}$, overweight and obesity ${ }^{10,11}$ physical inactivity, fiber intake ${ }^{12}$ and smoking ${ }^{13,14}$. However, the molecular mechanisms underlying the robust associations of CRP with these factors are not well-understood.

Epigenetic modifications such as the addition of a methyl group to a cytosine base of human DNA is commonly referred to as DNA methylation. This is a reversible process that affects gene expression. DNA methylation in white blood cells can be a consequence of exposure to risk factors such as subtle changes in regulatory regions of the genome in the setting of excess adiposity or smoking ${ }^{15,16}$ or a consequence of diseases like global changes of $\mathrm{CpG}$ methylation in cancer ${ }^{17}$. These $\mathrm{CpG}$ methylation changes affect gene expression patterns of different human tissues ${ }^{18}$, can be inherited across generations ${ }^{19}$ and differ between ethnicites ${ }^{18}$. Studying differential DNA methylation in relation to chronic inflammation could highlight pathways that link the risk factors to diseases and adverse effects.

In this study we performed a meta-analysis of trans-ethnic epigenome wide association studies (EWAS) on serum CRP in 22,774 participants. The large sample size of our study allowed us to create a reference list of CpGs robustly associated to CRP. In addition, our strategy could be used as a blueprint for generation of robust marker sets for any exposure similar to the field of genome wide association analysis. Our study suggests DNA methylation as consequences of CRP, identifies underlying factors of 
the signature such as $\mathrm{BMI}$ and smoking and gives a measure of the contribution to development of disease such as T2D and coronary artery disease.

\section{Results}

\section{Trans-ethnic Discovery}

We found a total of 1,765 markers significantly associated to serum CRP levels at a Bonferroni threshold $(P<1 e-7)$ in our trans-ethnic meta-analysis (Figure 1A) on 22,774 samples. Those were subdivided into African American and African Ancestries (AA), European Ancestries (EA) and South Asian Ancestries (SAA). Thirty studies provided summary statistics about the association of $\mathrm{CpG}$ methylation with serum CRP. We performed basic quality control of individual study association data, including replication within known CRP associated markers published by Ligthart et al ${ }^{20}$ as well as correlation of effect sizes between studies (Supplemental Figure 2 and 3). Mean age of participants ranged from 16 (NFBC1986) to 75.5 (CHS-W) years, BMI from $23.7 \mathrm{~kg} / \mathrm{m}^{2}$ (NFBC1986) to $32.9 \mathrm{~kg} / \mathrm{m}^{2}$ (BHS-W Median serum CRP values extended from $0.2 \mathrm{mg} / \mathrm{L} \mathrm{mg} / \mathrm{L}$ (NFBC1986) to $4 \mathrm{mg} / \mathrm{L} \mathrm{mg} / \mathrm{L}$ (EPIC Norfolk). Across all studies, $49.3 \%$ of the participants were female (Table 1$)$.

To prevent reporting false positive signals due to bias and unwanted variation such as population stratification, we applied Genomic Control (see online methods and Figure 1B). We then evaluated if these 1,765 CRP-associated methylation markers were significant across three ancestries in our study (AA, EA, SAA), and whether there were ancestry-specific DNA methylation markers. We defined CpGs as replicating in ancestry specific analysis if its P-value was below 0.05 and direction of effect was consistent in each ancestry specific analysis. Among markers identified in the trans-ethnic meta-analysis, 1,765 (100\%) were significant and showed a consistent direction of effect in EA (22 studies, N 14,568) alone, 1,408 (79.7\%, $\mathrm{N} \sim 3,430$ ) in AA (3 studies, $\mathrm{n} 3,430$ ) and 1,550 (87.8\%) in SAA meta-analyses (1 study, $\mathrm{N} 2,688$ ) (Figure 1C, Supplemental table 2). In addition, to the 1,765 markers discovered in trans-ethnic meta-analysis, we identified 62 Bonferroni significant markers in the EA only (Supplemental table 3) and 2 markers significant in SSA ancestries only (Supplemental table 3).

To further investigate differences between different ancestries, we plotted Z-scores across the ancestry specific meta-analysis (Supplementary Figure 4). However, we did not find any statistically significant evidence for heterogeneity in trans-ethnic meta-analysis. 


\begin{tabular}{|c|c|c|c|c|c|c|c|}
\hline Cohorts & $\mathbf{N}$ & Ethnicity & Age & Sex & CRP & BMI & smoking \\
\hline AIRWAVE & 1108 & EA & $\begin{array}{l}41.6 \\
(9.3)\end{array}$ & 40 & $1.0(2.8)$ & $\begin{array}{l}27.2 \\
(4.3)\end{array}$ & $\begin{array}{l}64.4 / 23.8 / \\
10.5\end{array}$ \\
\hline ARIC & 2182 & AA & $\begin{array}{l}56.1 \\
(5.75)\end{array}$ & 63.5 & $3.3(7.7)$ & $\begin{array}{l}30.1 \\
(6.2)\end{array}$ & $\begin{array}{l}44.9 / 30.4 \text { / } \\
24.6\end{array}$ \\
\hline ARIES & 777 & EA & $48(4.28)$ & 100 & $1.0(3.1)$ & $\begin{array}{l}26.4 \\
(5.1)\end{array}$ & $43.0 / 27.2 / 5.4$ \\
\hline BHS-B & 246 & AA & $\begin{array}{l}43.6 \\
(4.5)\end{array}$ & 45.1 & $2.1(2.5)$ & $\begin{array}{l}30.1 \\
(6.9)\end{array}$ & $\begin{array}{l}54.2 / 21.1 / \\
24.7\end{array}$ \\
\hline BHS-W & 572 & EA & $\begin{array}{l}43.2 \\
(4.5)\end{array}$ & 39.8 & $3.0(3.1)$ & $\begin{array}{l}32.9 \\
(8.9)\end{array}$ & $\begin{array}{l}49.8 / 16.1 / \\
34.1\end{array}$ \\
\hline BIOS-CODAM & 160 & EA & $\begin{array}{l}66.3 \\
(6.8)\end{array}$ & 46.2 & $2.2(5.4)$ & $\begin{array}{l}28.2 \\
(4.2)\end{array}$ & $\begin{array}{l}26.3 / 58.1 / \\
15.6\end{array}$ \\
\hline BIOS-LLS & 713 & EA & $\begin{array}{l}58.9 \\
(6.7)\end{array}$ & 52.2 & $1.2(5.5)$ & $\begin{array}{l}25.1 \\
(3.5)\end{array}$ & $\begin{array}{l}30.9 / 55.7 / / \\
13.3\end{array}$ \\
\hline BIOS-NTR & 894 & EA & $\begin{array}{l}33.6 \\
(15.1)\end{array}$ & 65.9 & $1.4(4.8)$ & $\begin{array}{l}24.0 \\
(4.0)\end{array}$ & $\begin{array}{l}57.2 \text { / } 24.8 \text { / } \\
17.9\end{array}$ \\
\hline BIOS-PAN & 166 & EA & $\begin{array}{l}63.2 \\
(9.4)\end{array}$ & 37.9 & $1.5(6.3)$ & $\begin{array}{l}25.6 \\
(3.6)\end{array}$ & $\begin{array}{l}39.8 \text { / } 32.5 / \\
27.6\end{array}$ \\
\hline CARDIOGENICS & 200 & EA & $56(6.7)$ & 16.6 & $0.5(6.4)$ & $\begin{array}{l}27.7 \\
(4.3)\end{array}$ & $\begin{array}{l}0.1759 / 82.41 \\
/ 0\end{array}$ \\
\hline CHS-B & 321 & AA & $\begin{array}{l}73.1 \\
(5.5)\end{array}$ & 62.3 & NA & $\begin{array}{l}28.7 \\
(5.2)\end{array}$ & $\begin{array}{l}44.8 \text { / } 37.4 \text { / } \\
54\end{array}$ \\
\hline CHS-W & 321 & EA & $\begin{array}{l}75.5 \\
(5.1)\end{array}$ & 60.4 & NA & $\begin{array}{l}26.7 \\
(5.0)\end{array}$ & $\begin{array}{l}44.2 \text { / } 41.4 \text { / } \\
11.8\end{array}$ \\
\hline EstBB-CTG & 306 & EA & $50(16.9)$ & 50 & $1.2(4.4)$ & $\begin{array}{l}26.4 \\
(5.6)\end{array}$ & $\begin{array}{l}51.3 / 30.4 / \\
18.3\end{array}$ \\
\hline EPIC Norfolk & 1278 & EA & $60(8.8)$ & 50.9 & $4(7.5)$ & $\begin{array}{l}27.2 \\
(4.4)\end{array}$ & $\begin{array}{l}45.1 / 39.3 / \\
15.6\end{array}$ \\
\hline EPICOR & 507 & EA & $\begin{array}{l}53.6 \\
(7.3)\end{array}$ & 37.9 & $1.1(2.5)$ & $\begin{array}{l}26.1 \\
(3.9)\end{array}$ & $\begin{array}{l}36.5 / 30.9 / \\
32.5\end{array}$ \\
\hline ESTHER-1a & 974 & EA & $62(6.5)$ & 50.08 & $1.6(5.6)$ & $\begin{array}{l}27.1 \\
(4.4)\end{array}$ & 47.6/33.7/18.7 \\
\hline ESTHER-1b & 543 & EA & $62(6.6)$ & 61.5 & $2.2(6.7)$ & $\begin{array}{l}27.5 \\
(4.8)\end{array}$ & 47.3/34.6/18.1 \\
\hline FHS & 2008 & EA & $66(9)$ & 55 & $2.5(2.9)$ & $\begin{array}{l}28.2 \\
(5.2)\end{array}$ & / NA / 7.1 \\
\hline GENOA-27k & 681 & AA & $\begin{array}{l}65.1 \\
(8.4)\end{array}$ & 72.1 & $0.35(1.4)$ & $\begin{array}{l}30.2 \\
(6.5)\end{array}$ & $\begin{array}{l}58.8 / 27.6 / \\
13.5\end{array}$ \\
\hline
\end{tabular}




\begin{tabular}{|c|c|c|c|c|c|c|c|}
\hline KORA & 1724 & EA & $61(8.8)$ & 51 & $1.3(3.7)$ & $\begin{array}{l}27.5 \\
(4.8)\end{array}$ & $41.7 / 43.7 / 14.5$ \\
\hline LBC & 258 & EA & $\begin{array}{l}72.1 \\
(0.5)\end{array}$ & 46.9 & $1.4(3.5)$ & $\begin{array}{l}27.6 \\
(4.3)\end{array}$ & 132/109/17 \\
\hline LLD & 695 & EA & $\begin{array}{l}45.3 \\
\text { (NA) }\end{array}$ & 58.2 & 1.7 (3.3) & $\begin{array}{l}24.6 \\
(4.2)\end{array}$ & NA \\
\hline LOLIPOP & 2688 & SAA & $50.3(10)$ & 31.5 & $2.3(7.2)$ & $\begin{array}{l}27.1 \\
(4.3)\end{array}$ & 82.6/8.6/8.8 \\
\hline NAS & 648 & EA & $\begin{array}{l}73.2 \\
(6.8)\end{array}$ & 0 & $3.3(6.1)$ & $28.1(4.1)$ & $\begin{array}{l}29.1 / 66.7 \text { / } \\
4.1\end{array}$ \\
\hline NFBC1966 & 727 & EA & $31(0.33)$ & 56.1 & $0.7(3.6)$ & $\begin{array}{l}24.5 \\
(3.5)\end{array}$ & $\begin{array}{l}51.7 / 21.3 / \\
25\end{array}$ \\
\hline NFBC1986 & 517 & EA & 16 & 53 & $0.2(3.4)$ & $\begin{array}{l}23.7 \\
(3.8)\end{array}$ & $\begin{array}{l}71.9 / 9.1 / \\
13.5\end{array}$ \\
\hline ROTTERDAM & 722 & EA & $\begin{array}{l}59.9 \\
(8.2)\end{array}$ & 53.7 & $2.6(4.7)$ & $\begin{array}{l}27.5 \\
(4.8)\end{array}$ & $\begin{array}{l}28.8 / 44.1 \\
/ 27.1\end{array}$ \\
\hline SHIP & 236 & EA & $\begin{array}{l}51.5 \\
(13.5)\end{array}$ & 51.3 & $2.3(4.0)$ & $27.1(4)$ & $\begin{array}{l}22.0 / 38.1 / \\
39.8\end{array}$ \\
\hline TWINSUK & 416 & EA & $59.3(8.7)$ & 100 & $1.6(7.8)$ & $25.6(4.6)$ & $59.4 / 30.8 / 9.9$ \\
\hline YFS & 186 & EA & $\begin{array}{l}44.2 \\
(3.4)\end{array}$ & 61 & $1.4(2.4)$ & 26.2 & NA \\
\hline
\end{tabular}

Table 1: Cohort characteristics. Column Cohorts gives all cohorts participating in the trans-ethnic metaanalysis in alphabetical order. $\mathrm{N}$ is the number of informative samples for this analysis. EA combines all European ancestries, AA combines all African Ancestries and SAA combines all South Asian ancestries. Age is given in years plus standard deviation. Sex is given as percent female in every cohort. CRP is the median of measured serum CRP levels in each cohort. BMI is body mass index. Smoking status given in percent as never smokers / former smokers / current smokers.

\section{DNA methylation correlation structure}

To determine which of the 1,765 CRP associated markers were independent and which were correlated, we assessed the DNA methylation correlation structure of these 1,765 markers across 4 studies ( $N$ 3920). We noticed that the correlation structure across the analyzed cohorts were similar despite of differences in mean age, ranging from 16 to 61 years, and detection platform (Supplemental Figure 5). Furthermore, we found that the correlation structure between CRP associated CpGs was consistent across chromosome borders (Figure 2A). However, the biggest contribution to the observed correlation structure was the physical proximity between 2 or more $\mathrm{CpGs}$. To better understand this contribution to the correlation structure we binned the correlation values according to their distance separately for each chromosome and displayed the results as boxplot (Figure 2B). The Pearson correlation coefficients 
depended on the distance between CpGs, with a drop below 0.2 at about $5 \mathrm{~kb}$. This average correlation value stayed stable for quite a distance throughout the genome. Thus, we decided to apply a $5 \mathrm{~kb}$ window to identify a set of independent uncorrelated loci. This strategy restricted our list of 1,765 marker to a list of 1,511 loci, which henceforth was used as input for any further analysis.

Because we observed coherent methylation patterns across chromosomes (Figure 2A), we attempted to identify clusters within our set of 1,511 independent loci. We used a density-based algorithm that suggested two correlation clusters within the analyzed data (Figure 2C). Mapping these group assignments back to the original data (color code in Figure $2 \mathrm{~A}$ ), we found that this assignment reflected the actual correlation values for most of the CpGs. Next, we looked into overlaps of the CpGs within each correlation cluster (Figure 2C) with genomic features. We found similar distributions of the two clusters in broad genomic features such as CpG islands, gene bodies, distance to transcription start sites, and HiC. However, we found differences in more specific genomic features, we detected in $22 \%$ of cluster $1 \mathrm{CpGs}$ being RELA (also known as nuclear factor NF-kappa-B p65 subunit) binding sites as opposed to $7.8 \%$ in cluster2 CpGs (Figure 4A). Overlaps to GO terms suggest different functional contributions of the 2 correlation sets (Figure 4C). The DNA methylation risk score analysis, however, did not show significant different effects of cluster1 CpGs or cluster2 CpGs on clinically relevant phenotypes (Supplemental table 22).

\section{Sensitivity analysis}

We compared the base model to a model additionally adjusted for BMI across all studies. All 1,765 markers showed consistent effect directions. The Pearson's correlation between Z-scores (denoted (Zscores)) from these two models was 0.985 (Figure $3 \mathrm{~A}$ ). Out of 187 published BMI associated $\mathrm{CpGs}^{22}$ we found $120 \mathrm{CpGs}$ within our list of 1,511 loci. In a subset of cohorts (see online methods), we evaluated possible influences of other risk factors on the CpG CRP associations. We did not observe any significant changes in the distribution of Z-scores when adjusting for additional risk factors such as smoking, lipids, insulin, BMI, hip circumference and waist circumference. (see online methods, Supplemental Figure 6). We observed a total of $22 \mathrm{CpGs}$ that changed the effect direction in at least one model in the sensitivity analysis. (Supplemental table 4). A total of $140 \mathrm{CpGs}$ had a nominal significant $\mathrm{P}$ value of heterogeneity, of which one marker had a Bonferroni significant $P$ value of heterogeneity.

\section{Driving forces of the CRP CpG association: Mendelian Randomization analyses}

$\mathrm{CpG}$ methylation can be a transient state. Thus, we studied whether or not $\mathrm{CpG}$ methylation of the 1,511 loci were causal for the altered serum CRP levels or if differences in $\mathrm{CpG}$ methylation is a consequence of altered CRP levels. It has been shown for BMI and Crohn's disease ${ }^{22,23}$ that differences in CpG methylation were a consequence of the investigated trait. Applying a similar strategy, we performed a 2sample Mendelian Randomization followed by a triangulation analysis (online methods). We combined genetic and epigenetic data from more than 7000 participants derived from 11 studies. We identified 709 
valid genetic instruments for $\mathrm{CpG}$ sites (Supplementary table 5), and found 8 loci showing Bonferroni significant effects of their genetic instruments on CRP levels. Thus, suggesting a causal effect of these 8 $\mathrm{CpGs}$ on serum CRP levels. We further investigated the overall association between $\mathrm{CpG}$ instruments and serum CRP levels in a triangulation analysis, with the following basic assumption: If the effect of a CpG on serum CRP is causal, it is possible to predict the effect of the genetic instrument (CpG-specific SNP) on CRP via the combination of the effect of the same SNP on CpG methylation and CpG methylation on CRP. This association is shown as scatter plot. (Figure 3C, Supplemental table 6). The analysis did not suggest an overall causal effect of $\mathrm{CpG}$ methylation on serum CRP levels (Figure 3C).

We further investigated if these $709 \mathrm{CpGs}$ might be consequence of altered serum CRP levels, but did not find Bonferroni significant associations between our genetic instruments for CRP and CpG methylation. This suggests no causal effects of CRP on any individual CpG (Supplemental table 7). Triangulation analysis, however, revealed that the majority of $\mathrm{CpGs}$ predicted the observed effects. We observed a Pearson Rho of $0.17(P=8.23 \mathrm{e}-06)$ (Figure 3D, Supplementary table 8 ) and the sign test revealed a $\mathrm{P}$ value of $1.27 \mathrm{e}-05$, suggesting a causal effect of serum CRP levels on the majority of CpGs.

\section{Driving forces of CRP CpG association: Mediation Analysis}

Mendelian Randomization highlighted complex associations between serum CRP levels and CpG methylation, thus we performed a mediation analysis. Mediation analysis was first performed on a small subset of data testing 6 different models (Online Methods, Supplementary table 9), which pointed towards 2 models for further exploration (Figure 3B): CRP being the mediator of a CpG methylation caused by BMl or by smoking (Figure 3B). We used data from 4 cohorts (N 3192) and performed mediation analyses according to Baron Kenney (online Methods, Figure 3B). We found $1136 \mathrm{CpGs}$ associated to BMI (nominally significant), of which 729 (64.1\%) show a significant P-value for CRP mediating the effect of BMI effects on DNA methylation, with 213 loci reaching Bonferroni significance (Supplementary table 2, 10).

We then evaluated possible effects of smoking on DNA methylation mediated by CRP (Figure 3B). We found 386 markers associated to CRP also associated to smoking. Out of this set we observed the effect of smoking on DNA methylation being mediated by CRP for 82 loci $(21.2 \%)$ of which 32 loci reach Bonferroni significance levels (Supplementary table 11).

\section{CRP associated CpGs in genomic and biological context}

Next, we evaluated if the $\mathrm{CpG}$ methylation signature was enriched within certain genomic features. We performed an overrepresentation analysis that mimicked the DNA methylation variation structure of our 1,511 loci (Online Methods). We compared the genomic positions of the CpG methylation signatures to histone modifications, DNase hypersensitivity and chromatin model from the Roadmap project ${ }^{21}$ as well as Hi-C data ${ }^{24}$ and Encode Transcription factor binding sites ${ }^{25}$ (Figure 4A). We found that CRP associated 
CpGs were enriched within gene bodies but were depleted around transcription start sites (Figure 4A, Supplementary table 12). We further found $\mathrm{CpG}$ markers enriched in euchromatin and depleted in heterochromatin (Hi-C compartments, Supplementary table 12 -17). Analysis of Roadmap's chromatin model showed $30 \%$ of all CRP associated CpGs situated within enhancer regions, whereas very few CpGs were on $\mathrm{EZH} 2$ binding sites, indicating a minor impact of $\mathrm{CpG}$ islands on the presented DNA methylation signatures (Figure 1, 4A).

We mapped the CRP methylation signature to histone marks across various tissues, however did not find distinct evidence for one tissue driving the CRP CpG signatures (Supplemental Figure 7, 8, supplementary tables 12-17).

Mapping the CRP specific DNA methylation signature to transcription factor binding sites revealed about $40 \%$ of loci being situated on Polymerase II subunit A binding site (POLR2A). This suggests DNA methylation is a key regulator of Polymerase II transcribed genes. Furthermore, we investigated the association between gene expression and CRP specific CpG signature (online methods). Out of 1,511 CRP associated loci $9 \%$ of CpGs were significantly associated with gene expression. $22 \mathrm{CpG}$ showed a positive association, whereas for the majority of $\mathrm{CpGs}(84 \mathrm{CpGs})$ an inverse relationship prevailed. This set of $106 \mathrm{CpGs}$ was subjected to gene set enrichment analysis, which showed a mixture of enrichments for metabolic and immune system processes (Figure 4B).

We also studied the overlap between CRP associated CpGs and published gene lists in GWAS and EWAS catalogue (Supplementary figure 9, supplementary table 19). Comparing the CRP signature to published EWAS results ${ }^{26}$ we found significant overlaps to $\mathrm{BMI}$, smoking, inflammatory diseases and cancer specific published gene lists (Figure 4C, Supplemental table 20 and 21).

\section{CRP associated CpGs in the clinical context}

Finally, we investigated the impact of CRP associated CpGs on clinically relevant phenotypes. We created a beta weighted risk score, following the same approach as for the polygenic risk scores in GWAS analysis. Associations between CRP methylation signatures and clinically relevant phenotypes were evaluated in the studies separately and then combined in a meta-analysis (Figure 5). There were no associations between cancer and the CpG risk score, however, we found the CRP risk score positively associated to weight, BMI and waist circumference ( $\mathrm{P}<6 \mathrm{E}-07$, Supplemental table 22). The CRP methylation risk score was also positively associated to several other inflammation markers including IL6, IL1RA, and tumor necrosis factor receptor (TNFR) ( $<<0.05$, supplemental table 22). We found strong associations of CRP methylation risk score to lung function (FEV1, FVC) as well as COPD and receipt of chemotherapy among breast cancer patients (Figure 5B). Finally, we found strong associations of the CRP associated methylation risk score with the tested cardiometabolic traits (Figure 5A). We calculated the adjusted relative risk based on published life time risk for cardiometabolic traits (online methods). This may be interpreted as follows: A full activation of the CRP DNA methylation risk score increases the risk for myocardial infarction by $20.3 \%$ (Figure 5A), indicating that if all discovered CpG loci would be 
either fully methylated or unmethylated according their direction of CRP association to have this impact on myocardial infarction. Similarly, full activation of the CRP CPG risk score increases the risk for COPD by $5.6 \%$, T2D risk by $11.3 \%$, the risk of developing hypertension by $11.9 \%$ and risk for coronary artery disease by $29 \%$.

\section{Discussion}

With a sample size of 22,774 this epigenome wide association study on CRP, an important marker for chronic low-grade inflammation, is one of the largest EWAS efforts thus far. In this study we identified a set of significantly associated CpGs that was $10 x$ larger than in previously published EWAS 22,27,28, even after application of a genomic control procedure, a conservative approach more typically performed in genome wide association studies ${ }^{29}$ (Figure 1B). Applying this strategy, the presented marker sets replicated well across ancestries (Figure 1C, Supplemental Figure 4) and proved to be stable in various sensitivity analyses (Figure 3A, Supplemental Figure 6).

One of the most interesting questions in terms of DNA methylation is its causal vs. consequential role: does the observed changed DNA methylation pattern contribute to risk for the associated trait, or is it a consequence? Mendelian Randomization, in which we use single nucleotide polymorphisms (SNP) as proxies for the individual $\mathrm{CpG}$ or the investigated trait, can help to answer this question ${ }^{30}$. If the SNPs associated with the CpGs discovered in this study are associated with CRP as well, we can infer a causal effect of the CpGs on chronic inflammation. In this case, DNA methylation would be the cause of changed serum CRP levels. Similar inference can be made with SNPs associated with chronic inflammation. This classical Mendelian Randomization can be extended to a triangulation analysis ${ }^{31}$, which is especially useful for DNA methylation studies. In triangulation analysis the effect size of the instrument-outcome association should match the combined effect size of the instrument-exposure association and exposure-outcome association. It has been shown that BMI as well as Crohn's disease causes DNA methylation changes ${ }^{22,23}$. Our Mendelian Randomization results suggest that the observed DNA methylation are likely a consequence of low-grade inflammation (Figure 3D). These results, however, are less striking than similar results observed for BMI and Crohn's disease. This might be due to the increased number of markers evaluated in this study compared to previous studies or due to the complex relationship between low-grade inflammation and metabolic syndrome, smoking, stress and many other factors ${ }^{32}$.

To put DNA methylation into context with other risk factors for low-grade inflammation we performed a mediation analysis. We observed more Bonferroni significant markers than previous studies ${ }^{33,34}$ by a factor of about 10, and assessed a total of 6 different mediation models (Online Methods, Supplementary table 9). We observed that a large proportion of the CRP associated DNA methylation was caused by BMI (Figure 3B) and a smaller fraction of the described $\mathrm{CpG}$ signature was produced by smoking.

The CRP DNA methylation signature includes a mixture of $\mathrm{CpGs}$ with evidence that they may play a central role in many cardiovascular and other diseases and CpGs that may be consequences of 
inflammation. One of the strongest markers for BMI CRP mediation is PHOSPHO1 (cg02650017). We found evidence that association of this marker, previously linked to $\mathrm{BMI}^{22}$, is actually due to the effect of BMI on CRP (Supplementary table 9, C2 path for cg02650017 not significant). Similarly, we discovered that MPRIP methylation (cg23842572), which was associated with smoking in a previous large-scale study associated to smoking ${ }^{35}$, was also mediated by CRP. Interestingly, the very same CpG (cg23842572) was associated with all-cause mortality. ${ }^{36}$

Similar to other complex trait DNA methylation association studies we detected low-grade inflammation associated CpGs predominantly located in open chromatin structures ${ }^{37,38}$, enhancers and other regulatory regions in the genome and depleted in $\mathrm{CpG}$ island and related structures (Figure 1A, Figure 4). We replicated the published association between increased DNA methylation at AIM2 and lower serum CRP levels and lower expression of $A I M 2^{20}$. Additionally, our study suggests that this effect is due to a BMI à CRP à DNA methylation (Supplementary table 9, C2 path for cg10636246 not significant). Furthermore, we observed decreased DNA methylation associated with higher levels of CRP and higher expression levels of NOD2, an established marker for chronic inflammation ${ }^{39}$, which again was due to a BMI à CRP à DNA methylation mediation effect (Figure 3B, Supplementary table 9, cg01243823).

The connection between low-grade inflammation and adverse health outcomes is well established ${ }^{40,41}$, thus we investigated if $\mathrm{CpG}$ methylation caused by low-grade inflammation explains these associations. On a global level, creating a DNA methylation risk score, we found strong evidence for this notion. However, individual DNA methylation changes also suggest this. In a large-scale nested case control study Chambers JC et al ${ }^{42}$ identified $5 \mathrm{CpGs}$ affecting T2D risk. All $5 \mathrm{CpGs}$ were associated with $\mathrm{CRP}$ in this study and thus included in our risk score. The DNA methylation signal of two markers, PHOSPHO1 and SOCS3, were caused by a BMI à CRP à DNA methylation mediation. This highlights the important contribution of inflammation to T2D development and the importance of our findings to improve the understanding of existing data and how this dataset can serve as a reference for research into chronic inflammation. Similarly to T2D, we find four out of the six top markers associated with FEV1/FVC in a recent large scale meta-analysis ${ }^{43}$. The signal from one marker in the AHRR gene could be back traced to a smoking à CRP à DNA methylation mediation effect found in our study.

This study has limitations: We assayed DNA methylation in blood and thus we naturally investigated rather the consequences of changed CRP levels than the causes, as CRP is primarily synthesized in the liver $^{44}$ and adipose tissue ${ }^{45}$. Our study provides only a snapshot of DNA methylation changes associated with chronic inflammation, as we were limited to loci present on the Illumina Infinium Human Methylation450 Bead chips. The fact that more than 100,000 probes are situated on CpG islands ${ }^{46}$, which as we and others ${ }^{28,37}$ showed, further decreases the number of actual analysed genomic loci. Due to limited data availability, we investigated only a small number of possible underlying reasons for the CRP associated DNA methylation changes. Apart from smoking and BMI there might be other risk factors that actually drive the CRP signature ${ }^{32}$. 
This large scale setting, however, gives rise to other challenges, including the risk of false positives due to technical as well as unknown biological influences alongside with cellular heterogeneity ${ }^{47}$, which can be amplified in larger samples.

The strengths of our study are its sample size and its multi-ethnic discovery combined with a stringent analysis controlling for unwanted variation, allowing conclusions relevant for public health and disease management to be drawn. The large number of samples guaranties stable, reproducible results. The novel discovered signature shows higher replication rates across ancestries than earlier EWAS on CRP with smaller sample sizes ${ }^{20}$. Furthermore, studies included in meta-analysis used different data normalization strategies and different microarray technologies, which makes the resulting DNA methylation signature very generalizable and likely to be reproducible in many contexts.

Since DNA methylation is a reversible process ${ }^{48}$, our low-grade inflammation associated DNA methylation signatures could serve as a valuable tool to monitor if changes in lifestyle are effectively decreasing the risk of adverse health outcomes. They could be used to monitor efficacy of personalized interventions or may even pave the way for new epigenetic treatments. In a healthy population the DNA methylation signature can be applied as a proxy for chronic inflammation, and serve as indicator for the transition between metabolically healthy obesity and obesity that most likely lead to adverse health outcomes.

In conclusion, we identified a robust set of $\mathrm{CpGs}$ associated with chronic inflammation in a large-scale multi-ethnic discovery analysis. Our analysis suggests that the discovered DNA methylation signature was largely a consequence of chronic inflammation that can be traced back to a mosaic of underlying driving factors such as smoking and BMI. The presented DNA methylation signature could be applied to understand the influence of low-grade inflammation in any existing or novel epigenome wide association study and we hope that this large-scale meta-analysis inspires similar efforts to produce reliable signature for other complex traits. Most importantly, our study suggests that a sizable proportion of the impact from low-grade inflammation on the risk of heart disease, hypertension, T2D and COPD is conveyed by DNA methylation, which implies that these effects might be reversible when changing the underlying causes such as BMI and smoking.

\section{References}

1. Danesh, J. et al. Low grade inflammation and coronary heart disease: prospective study and updated meta-analyses. BMJ 321, 199-204 (2000).

2. Dehghan, A. et al. Risk of type 2 diabetes attributable to C-reactive protein and other risk factors. Diabetes Care 30, 2695-9 (2007).

3. Schmidt, M.I. et al. Markers of inflammation and prediction of diabetes mellitus in adults (Atherosclerosis Risk in Communities study): a cohort study. Lancet 353, 1649-52 (1999). 
4. Saukkonen, T. et al. Adipokines and inflammatory markers in elderly subjects with high risk of type 2 diabetes and cardiovascular disease. Sci Rep 8, 12816 (2018).

5. Danesh, J. et al. C-reactive protein and other circulating markers of inflammation in the prediction of coronary heart disease. N Engl J Med 350, 1387-97 (2004).

6. Leuzzi, G. et al. C-reactive protein level predicts mortality in COPD: a systematic review and metaanalysis. Eur Respir Rev 26(2017).

7. Kim, J. et al. A double-hit of stress and low-grade inflammation on functional brain network mediates posttraumatic stress symptoms. Nat Commun 11, 1898 (2020).

8. Valkanova, V., Ebmeier, K.P. \& Allan, C.L. CRP, IL-6 and depression: a systematic review and metaanalysis of longitudinal studies. J Affect Disord 150, 736-44 (2013).

9. Ligthart, S. et al. Genome Analyses of $>200,000$ Individuals Identify 58 Loci for Chronic Inflammation and Highlight Pathways that Link Inflammation and Complex Disorders. Am J Hum Genet 103, 691-706 (2018).

10. Timpson, N.J. et al. C-reactive protein levels and body mass index: elucidating direction of causation through reciprocal Mendelian randomization. Int J Obes (Lond) 35, 300-8 (2011).

11. Sarin, H.V. et al. Substantial fat mass loss reduces low-grade inflammation and induces positive alteration in cardiometabolic factors in normal-weight individuals. Sci Rep 9, 3450 (2019).

12. Johansson-Persson, A. et al. A high intake of dietary fiber influences C-reactive protein and fibrinogen, but not glucose and lipid metabolism, in mildly hypercholesterolemic subjects. Eur J Nutr 53, 39-48 (2014).

13. Kasapis, C. \& Thompson, P.D. The effects of physical activity on serum C-reactive protein and inflammatory markers: a systematic review. J Am Coll Cardiol 45, 1563-9 (2005).

14. Liu, Y.Z., Wang, Y.X. \& Jiang, C.L. Inflammation: The Common Pathway of Stress-Related Diseases. Front Hum Neurosci 11, 316 (2017).

15. Wiklund, P. et al. DNA methylation links prenatal smoking exposure to later life health outcomes in offspring. Clin Epigenetics 11, 97 (2019).

16. Wahl, S. et al. Epigenome-wide association study of body mass index, and the adverse outcomes of adiposity. Nature 541, 81-86 (2017).

17. Baylin, S.B. DNA methylation and gene silencing in cancer. Nat Clin Pract Onco/ 2 Suppl 1, S4-11 (2005). 
18. Lokk, K. et al. DNA methylome profiling of human tissues identifies global and tissue-specific methylation patterns. Genome Biol 15, r54 (2014).

19. Heard, E. \& Martienssen, R.A. Transgenerational epigenetic inheritance: myths and mechanisms. Cell 157, 95-109 (2014).

20. Ligthart, S. et al. DNA methylation signatures of chronic low-grade inflammation are associated with complex diseases. Genome Bio/ 17, 255 (2016).

21. Kundaje, A. et al. Integrative analysis of 111 reference human epigenomes. Nature 518, 317-30 (2015).

22. Wahl, S. et al. Epigenome-wide association study of body mass index, and the adverse outcomes of adiposity. Nature 541, 81-86 (2017).

23. Somineni, H.K. et al. Blood-Derived DNA Methylation Signatures of Crohn's Disease and Severity of Intestinal Inflammation. Gastroenterology 156, 2254-2265 e3 (2019).

24. Rao, S.S. et al. A 3D map of the human genome at kilobase resolution reveals principles of chromatin looping. Cell 159, 1665-80 (2014).

25. Wang, J. et al. Factorbook.org: a Wiki-based database for transcription factor-binding data generated by the ENCODE consortium. Nucleic Acids Res 41, D171-6 (2013).

26. Li, M. et al. EWAS Atlas: a curated knowledgebase of epigenome-wide association studies. Nucleic Acids Res 47, D983-D988 (2019).

27. Reese, S.E. et al. Epigenome-wide meta-analysis of DNA methylation and childhood asthma. $J$ Allergy Clin Immunol 143, 2062-2074 (2019).

28. Zaghlool, S.B. et al. Epigenetics meets proteomics in an epigenome-wide association study with circulating blood plasma protein traits. Nat Commun 11, 15 (2020).

29. Yang, J. et al. Genomic inflation factors under polygenic inheritance. Eur J Hum Genet 19, 807-12 (2011).

30. Davies, N.M., Holmes, M.V. \& Davey Smith, G. Reading Mendelian randomisation studies: a guide, glossary, and checklist for clinicians. BMJ 362, k601 (2018).

31. Lawlor, D.A., Tilling, K. \& Davey Smith, G. Triangulation in aetiological epidemiology. Int J Epidemiol 45, 1866-1886 (2016).

32. Furman, D. et al. Chronic inflammation in the etiology of disease across the life span. Nat Med 25, 1822-1832 (2019). 
33. Tobi, E.W. et al. DNA methylation as a mediator of the association between prenatal adversity and risk factors for metabolic disease in adulthood. Sci Adv 4, eaao4364 (2018).

34. Kular, L. et al. DNA methylation as a mediator of HLA-DRB1*15:01 and a protective variant in multiple sclerosis. Nat Commun 9, 2397 (2018).

35. Joehanes, R. et al. Epigenetic Signatures of Cigarette Smoking. Circ Cardiovasc Genet 9, 436-447 (2016).

36. Zhang, Y. et al. DNA methylation signatures in peripheral blood strongly predict all-cause mortality. Nat Commun 8, 14617 (2017).

37. Huan, T. et al. Genome-wide identification of DNA methylation QTLs in whole blood highlights pathways for cardiovascular disease. Nat Commun 10, 4267 (2019).

38. Xu, C.J. et al. DNA methylation in childhood asthma: an epigenome-wide meta-analysis. Lancet Respir Med 6, 379-388 (2018).

39. Ferrero-Miliani, L., Nielsen, O.H., Andersen, P.S. \& Girardin, S.E. Chronic inflammation: importance of NOD2 and NALP3 in interleukin-1 beta generation. Clin Exp Immuno/ 147, 227-35 (2007).

40. Prins, B.P. et al. Investigating the Causal Relationship of C-Reactive Protein with 32 Complex Somatic and Psychiatric Outcomes: A Large-Scale Cross-Consortium Mendelian Randomization Study. PLoS Med 13, e1001976 (2016).

41. Bautista, L.E. Inflammation, endothelial dysfunction, and the risk of high blood pressure: epidemiologic and biological evidence. J Hum Hypertens 17, 223-30 (2003).

42. Chambers, J.C. et al. Epigenome-wide association of DNA methylation markers in peripheral blood from Indian Asians and Europeans with incident type 2 diabetes: a nested case-control study. Lancet Diabetes Endocrino/ 3, 526-534 (2015).

43. Imboden, M. et al. Epigenome-wide association study of lung function level and its change. Eur Respir J 54(2019).

44. Sproston, N.R. \& Ashworth, J.J. Role of C-Reactive Protein at Sites of Inflammation and Infection. Front Immuno/ 9, 754 (2018).

45. Ouchi, N. et al. Reciprocal association of C-reactive protein with adiponectin in blood stream and adipose tissue. Circulation 107, 671-4 (2003).

46. Pidsley, R. et al. Critical evaluation of the Illumina MethylationEPIC BeadChip microarray for whole-genome DNA methylation profiling. Genome Bio/ 17, 208 (2016). 
47. van Iterson, M., van Zwet, E.W. \& Heijmans, B.T. Controlling bias and inflation in epigenome- and transcriptome-wide association studies using the empirical null distribution. Genome Bio/ 18, 19 (2017).

48. Wu, H. \& Zhang, Y. Reversing DNA methylation: mechanisms, genomics, and biological functions. Cell 156, 45-68 (2014).

\section{Figures}

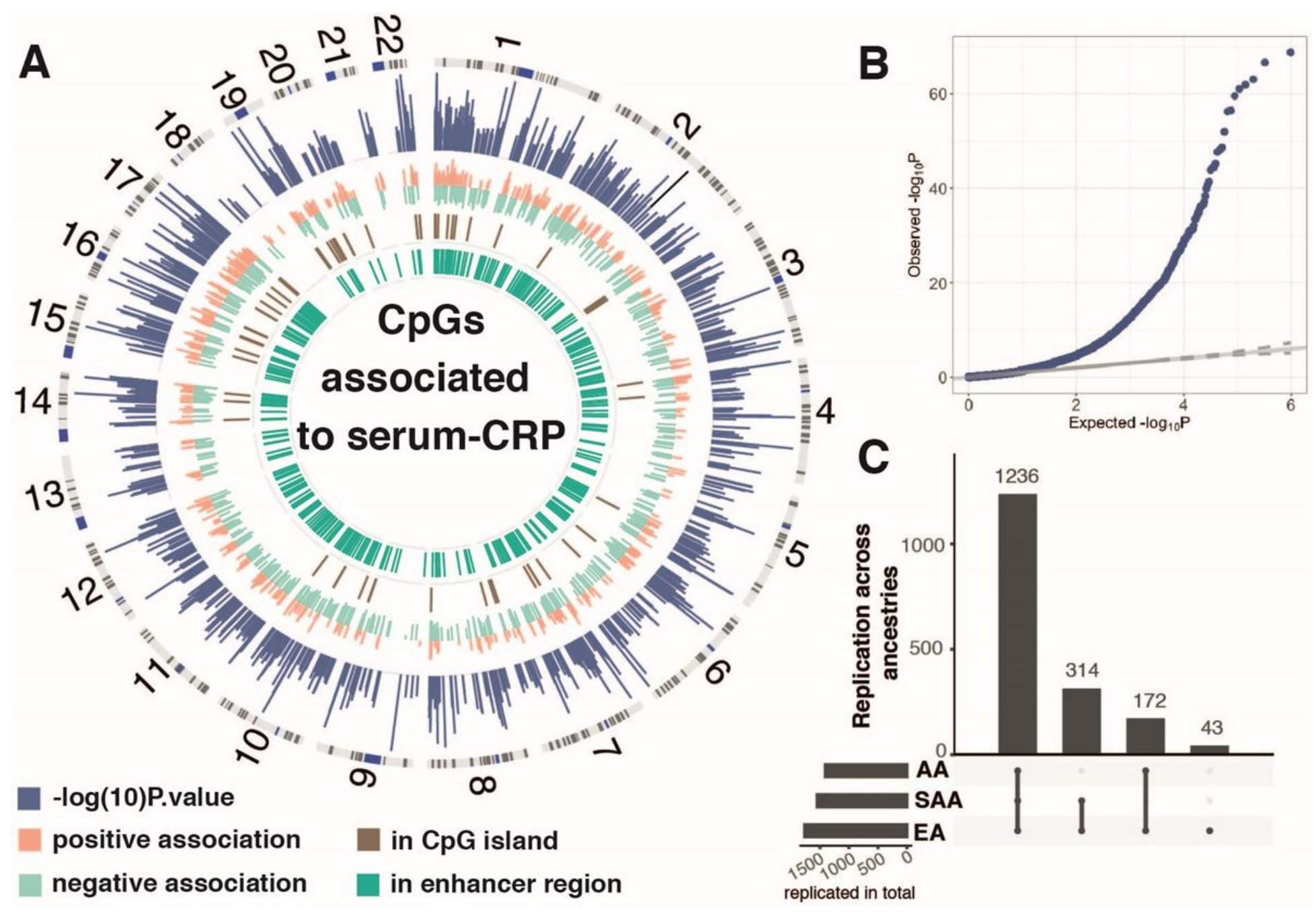

Figure 1

Results of trans-ethnic meta-analysis. Panel A is a circos plot representation of the trans-ethnic metaanalysis. Outermost track is chromosome number followed by ideogram. The second track in blue is the Manhattan plot of the CpG CRP association results. Next track (in orange and light green) are effect sizes of CpG CRP associations, where orange represents positive associations and light green negative. Track represented in brown track colour gives the overlap between the 1765 CRP associated CpG markers with $\mathrm{CpG}$ island in the genome. The innermost track (in dark green) gives the overlap with enhancer regions as defined by Roadmap project21. Panel B is a qqplot of the genomic control corrected P-values from the trans-ethnic meta-analysis. Panel $\mathrm{C}$ shows replication rates of 1765 across ancestries. Each bar gives the 
number of replicated $\mathrm{CpGs}$ across ancestries indicated as dots below the barplot. Horizontal bars reflect the total number of replicated CpGs per ancestry group.

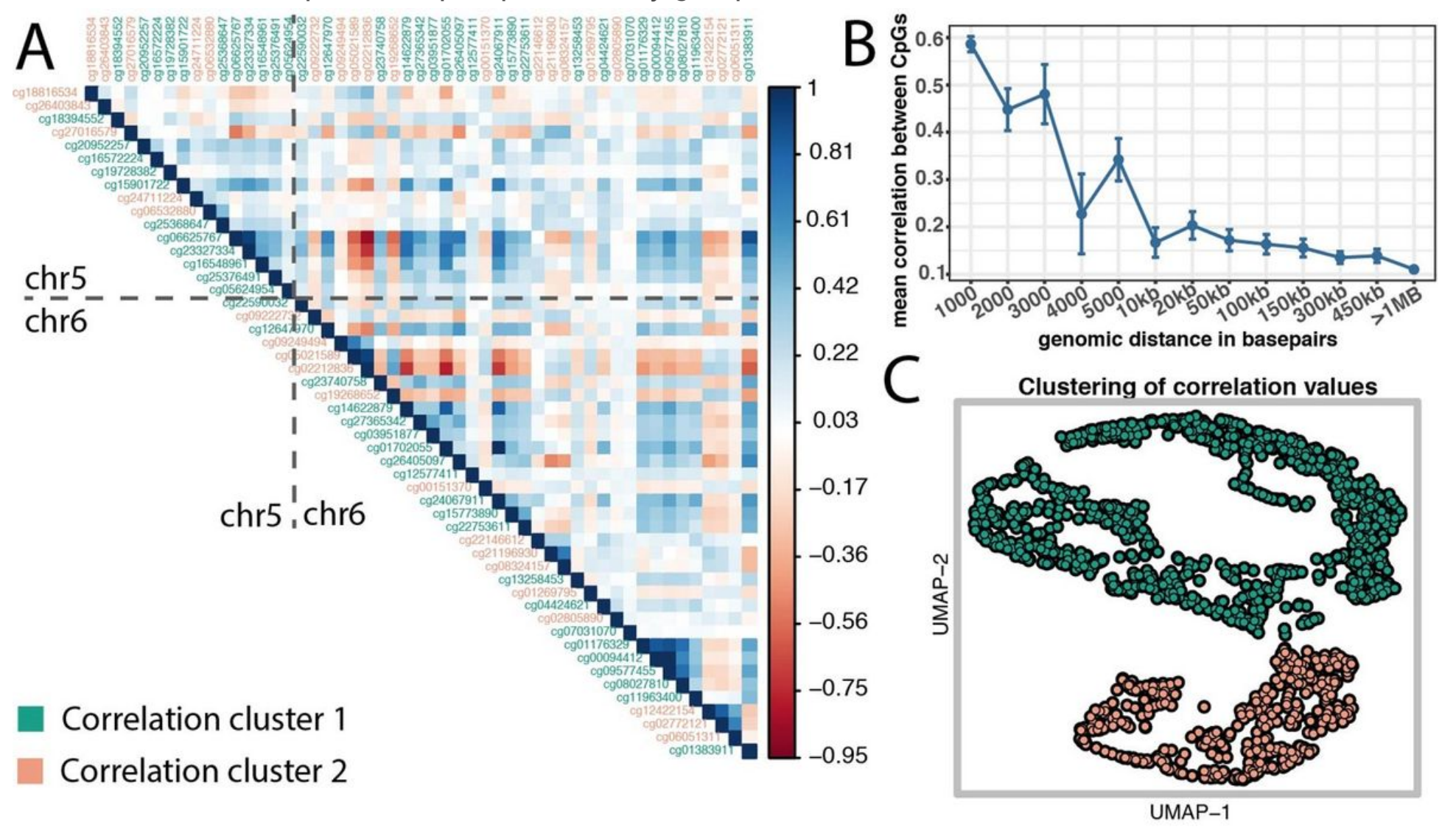

Figure 2

Correlation structure of CRP associated CpG methylation. Panel A gives meta-analysed correlation values (Pearson Rho) across 4 cohorts. Displayed are all CRP associated CpGs from a genomic region from chromosome 5 alongside with CRP associated CpGs on chromosome 6. CpG ids are colour- coded according to correlation clusters. Panel B CpGs correlation depending on distance. Correlation values were binned according their distance to each other. $X$ axis gives distance between $\mathrm{CpGs}$. $\mathrm{Y}$ axis gives mean Pearson Rho observed each distance bin. Panel $\mathrm{C}$ is a UMAP representation of correlation values of the 1,511 independent loci. Dots are colour- coded according their correlation cluster membership. 


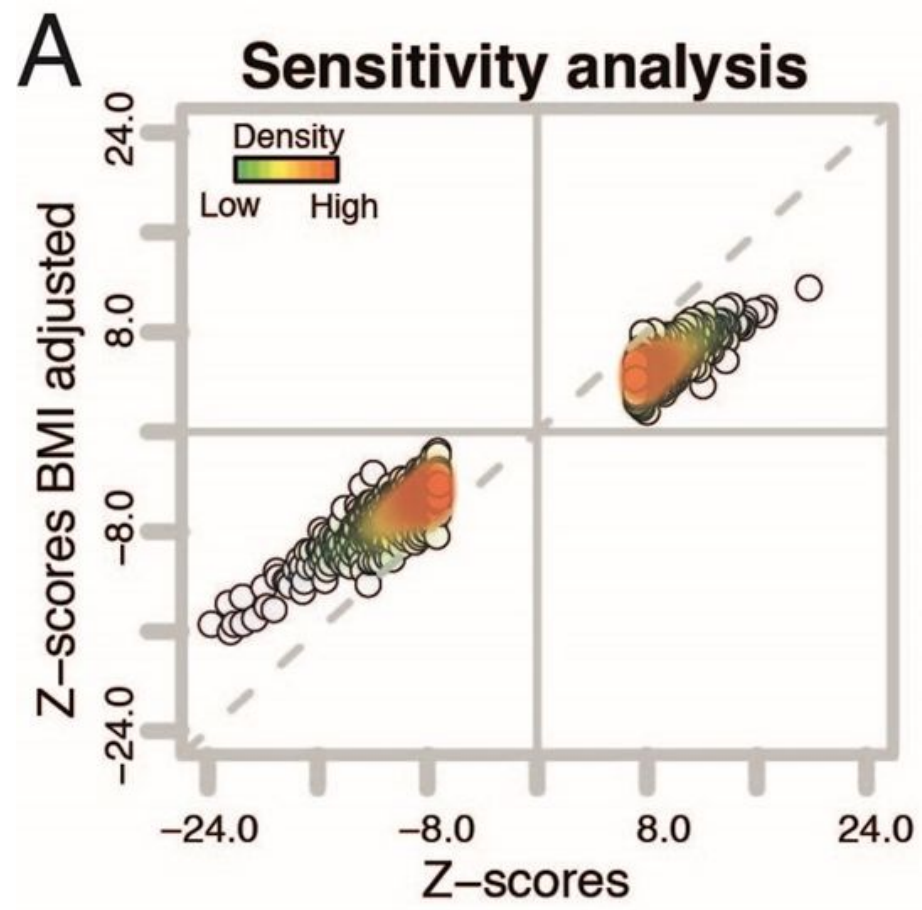

B Mediation analysis
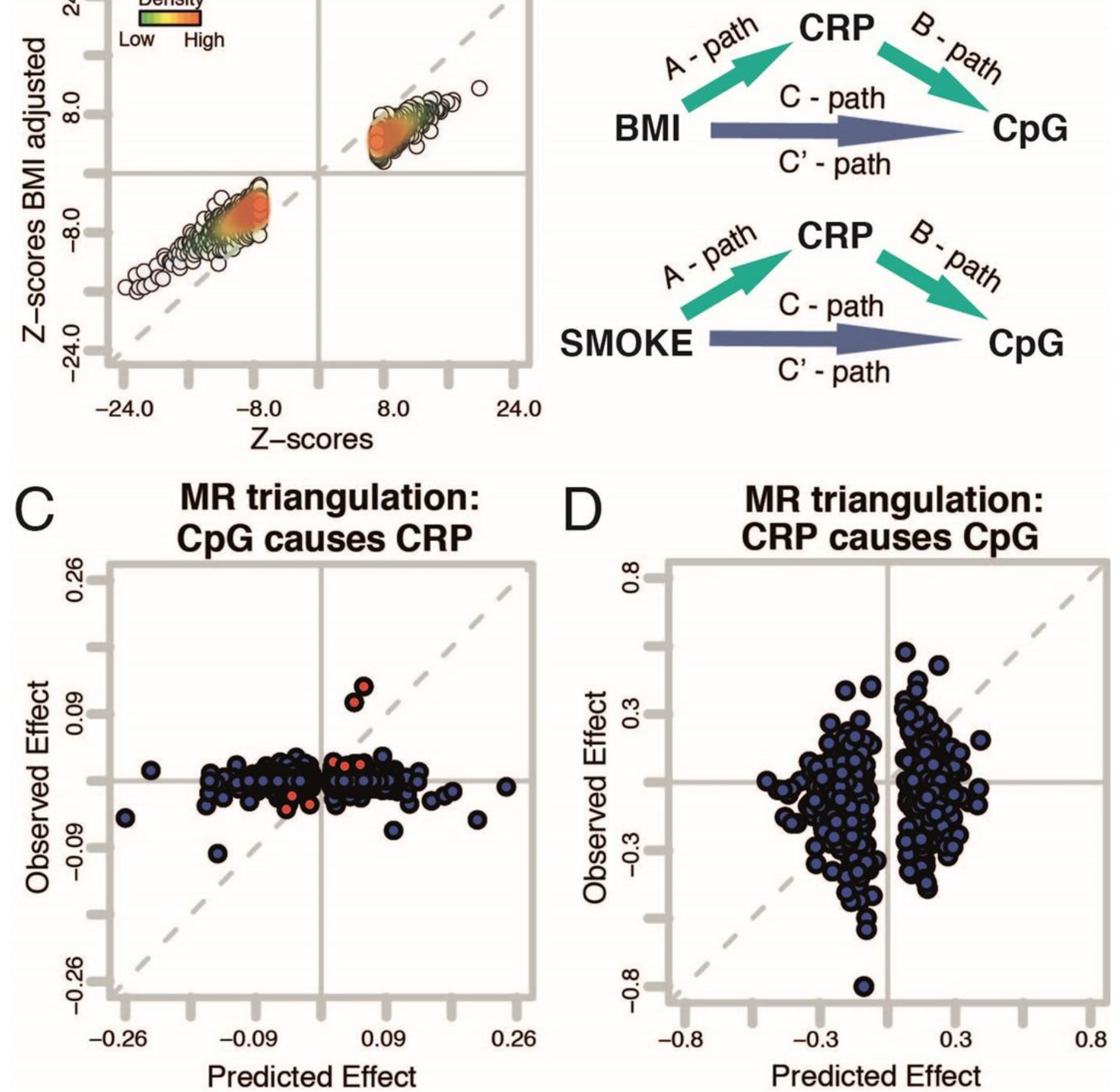

Figure 3

Driving forces of $\mathrm{CpG}$ signature. Panel $\mathrm{A}$ is a comparison of $\mathrm{Z}$ scores from the sensitivity analysis. Each dot represents a coefficient from the 1,511 CRP associated loci. The $X$ axis gives $Z$-scores derived from base model as applied in trans-ethnic meta-analysis. The $Y$ axis gives results from the same analysis adjusted for BMI. Panel B gives an overview of applied mediation analysis models. Panels C and D are representations of the Mendelian Randomization triangulation analysis. Each dot represents a CpG. The 
$Y$ axis is the observed effect, which is the association between the genetic instrument and outcome. The observed effects for Panel C originate from CpG instruments (SNPs) vs serum CRP levels. The predicted effect is the combined effect from the SNP CpG association and the $\mathrm{CpG}$ serum CRP association. Observed effects for Panel $D$ are the associations between a polygenic risk score for CRP (instruments) and $C p G$ methylation. The predicted effects for panel $D$ are the combined effects from the polygenic risk score for CRP (instruments) serum CRP association and serum CRP CpG methylation association (CRPGenetic risk score CRP association $x$ CRP CpG association). Observed effect is the association of the polygenic risk score for CRP (instruments) to $\mathrm{CpG}$ methylation (CRPGenetic risk score CpG association)
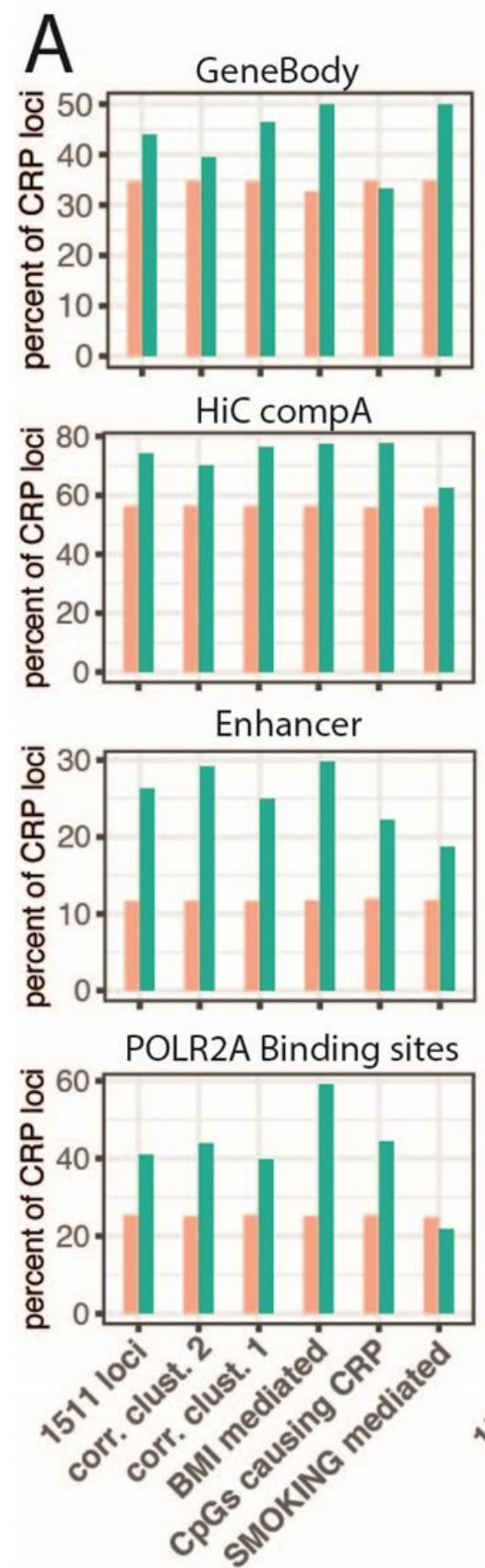

TranscriptionStartSite

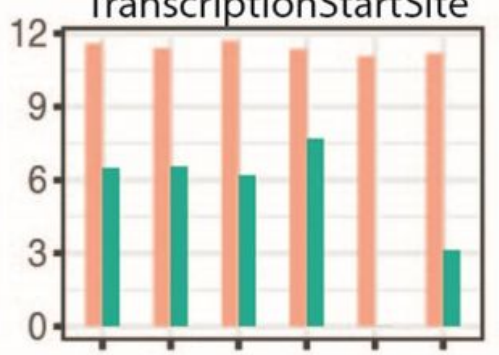

$\mathrm{HiC}$ compB
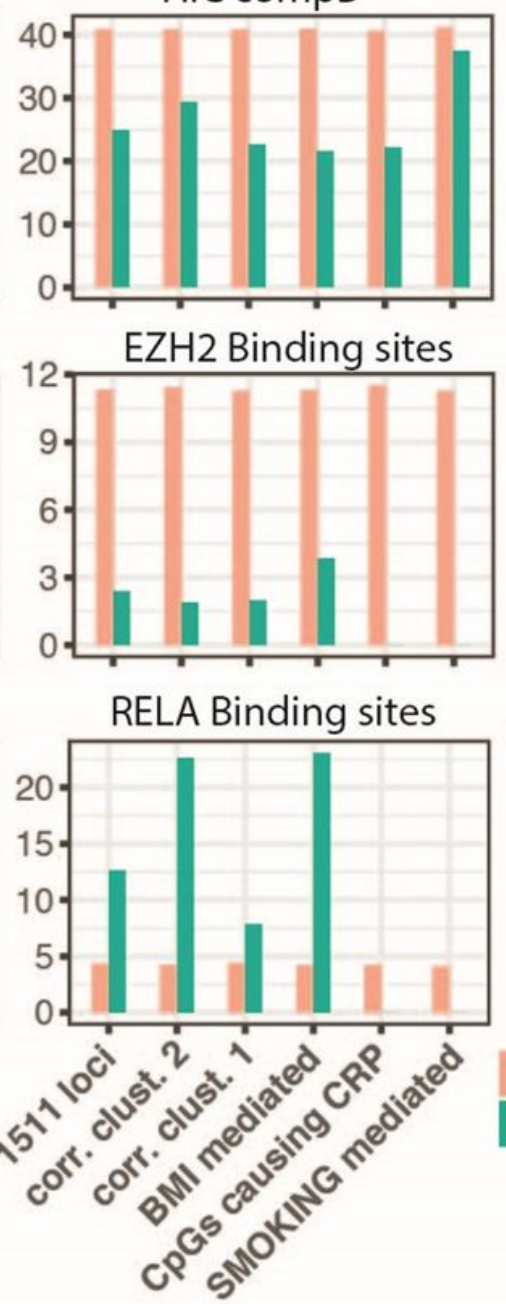

GO term enrichments

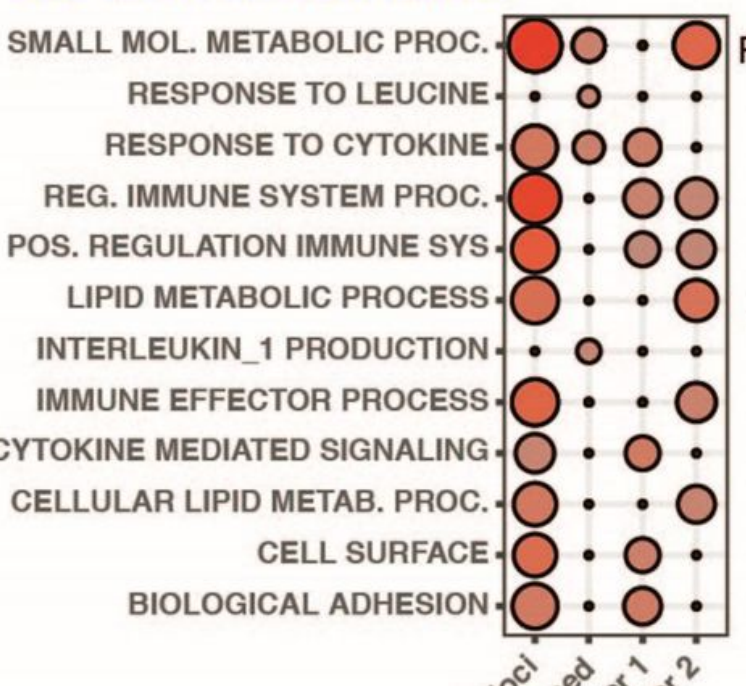

EWAS catalogue

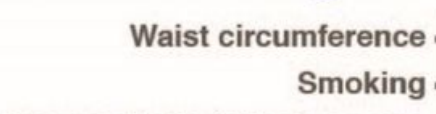

Pancreatic ductal adenocarc.

Fetal vs adult liver

Current vs never smoking

Clear cell renal carcinoma

$\mathrm{C}$-reactive protein

Psoriasis

Papillary thyroid carcinoma

Crohn's disease

Body mass index

Asthma

Alcohol consumption

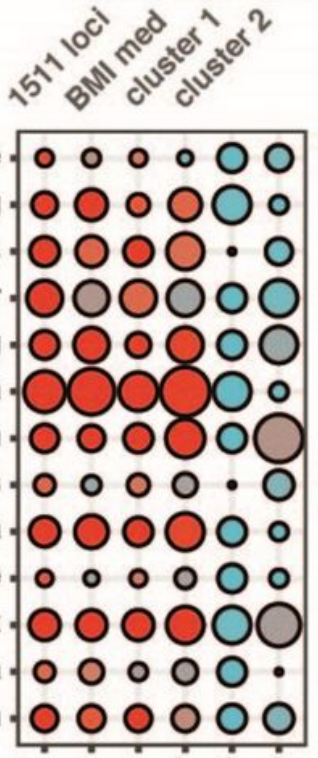

expected

observed
B

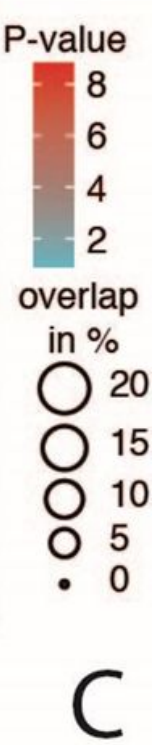

overlap

in \%

40

O 30

○ 20

○ 10

- 0

\section{P-value}

10.0

5.0

0.0

Figure 4 
Overrepresentation analysis. Panel A gives the percentage of each CRP associated gene set that overlaps with selected genomic feature. Orange bars represent overlapping features by chance; green bars give the percentage that actually overlaping with the CRP associated CpGs. Transcription start site and enhancer genomic region were used as defined by the Roadmap project. HiC regions were as reported in GSE63525, where component A was connected to highly transcribed genomic regions and component $B$ to heterochromatin. Panel B shows enrichment analysis between CRP associated CpG that were significantly associated with mRNA expression. P-value is for the overlap, given as negative $\log 10$. Percent overlap indicates the percentage of $\mathrm{CpGs}$ present in each $\mathrm{GO}$ term set. Panel $\mathrm{C}$ gives overlaps between CpGs observed in this study and published gene lists from large scale EWAS.

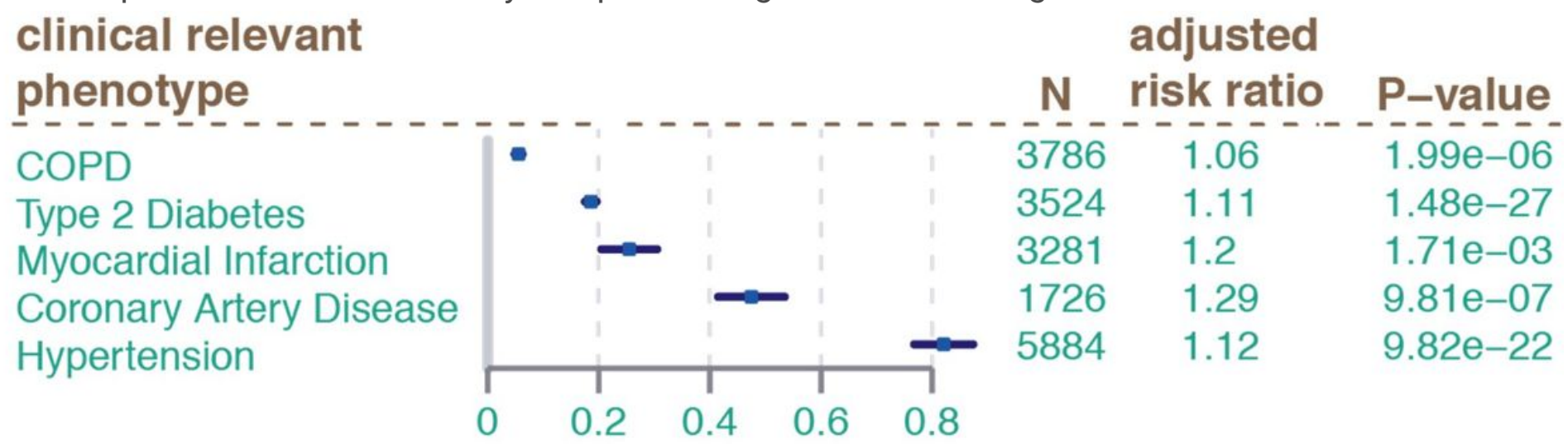

\section{clinical relevant}

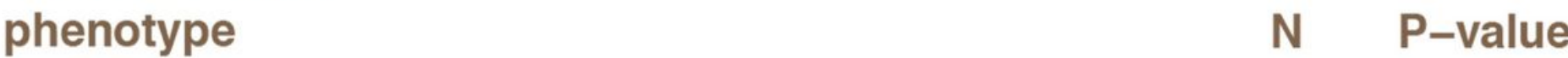

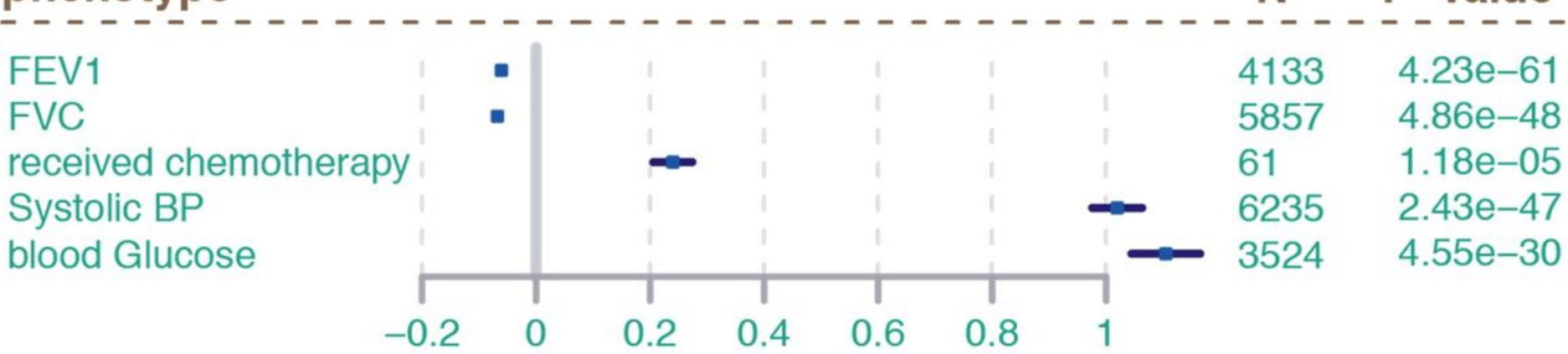

\section{Figure 5}

Associations of CRP DNA methylation signature to clinically relevant phenotypes. Forest plots give estimate from logistic regression (logODDs) and confidence intervals of $\mathrm{CpG}$ risk score regression against relevant phenotypes. $\mathrm{N}$ is the number of samples included in analysis. For continuous traits such as FEV1, FVC, systolic BP and blood glucose estimates from linear regression including confidence intervals are given.

\section{Supplementary Files}


This is a list of supplementary files associated with this preprint. Click to download.

- BIOSConsortiumlnfo.docx

- BIOSConsortiumInfo.docx

- SupplementaryResults20210705.docx

- supplementalexcel20210705.xlsx

- methods20210705.docx 